\title{
Violencia laboral en el Comité ejecutivo nacional del Sindicato Único de Trabajadores Electricistas de la República Mexicana (SUTERM): estudio de caso
}

FIGURAS REVISTA ACADÉMICA

DE INVESTIGACIÓN

ISSN 2683-2917

Vol. 3, núm. 1,

noviembre 2021-febrero 2022

https://doi.org/10.22201/

fesa.figuras.2021.3.1

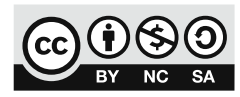

Esta obra está bajo una Licencia Creative Commons AtribuciónNoComercial-Compartirlgual

4.0 Internacional.

Recibido: 16 de marzo de 2021

Revisado:

13 de abril de 2021

Aceptado:

19 de julio de 2021

https://doi.org/10.22201/

fesa.figuras.2021.3.1.195
Labor violence within the National executive committee of the Union of Electrical Workers of the Mexican Republic (SUTERM, spanish acronym): a case study

\section{(D) Víctor Manuel Rangel-Cortés}

Universidad Nacional Autónoma de México.

Facultad de Estudios Superiores Acatlán

(D) Indra Orquídea Flores-García

Universidad Nacional Autónoma de México.

Facultad de Estudios Superiores Acatlán

(D) Juan Pablo Aguilar-Guillen

Universidad Nacional Autónoma de México.

Facultad de Estudios Superiores Acatlán

Resumen: Esta investigación se enfoca en conocer un caso particular de violencia laboral ocurrido dentro del Comité ejecutivo nacional del Sindicato Único de Trabajadores Electricistas de la República Mexicana. El objetivo es analizar dicho caso, desde la perspectiva de la víctima, ocurrido en ese sindicato. El enfoque teórico son las paradojas del derecho planteadas por Augusto Sánchez Sandoval. Se hace análisis cualitativo con base en una entrevista a la víctima. Los resultados muestran que la víctima sufrió daños en su integridad, salud, seguridad y autoestima, así como 
violencia institucional. Como conclusión principal se señala que la violencia laboral consentida por las mujeres en el entorno sindical está condicionada por la relación de poder que pone en manos del patrón su bienestar económico, el de su familia y personas allegadas.

Palabras clave: Violencia de género, sindicato, entorno laboral, violencia laboral, discriminación.

Abstract: This research focuses on knowing a particular case of gender violence that occurred within the Union of Electrical Workers of the Mexican Republic. The objective is to analyze a case, from the victim's perspective, that occurred in that union. The theoretical approach is the paradoxes of law raised by Augusto Sánchez Sandoval. A qualitative analysis is made based on an interview with the victim. The results show that the victim suffered damage to his integrity, health, safety and self-esteem, as well as institutional violence. As a main conclusion, the acceptance of gender violence by women in the work environment is conditioned by the power relationship that places the economic well-being of the woman, her family and close associates in the hands of the employer.

Keywords: Gender violence, union, work environment, workplace violence, discrimination.

\section{Introducción}

Este proyecto se enfoca en conocer, con base en una investigación cualitativa, un caso particular de violencia de género ocurrido dentro del Comité ejecutivo nacional del Sindicato Único de Trabajadores Electricistas de la República Mexicana (SUTERM).

La pregunta de investigación es: ¿cuáles son las características de la violencia de género contra una mujer en el entorno laboral de un sindicato? La hipótesis diseñada, aplicada sólo al caso que se analiza, es: existen sindicatos en los que las mujeres se someten al poder y violencia laboral del patrón, condicionadas por factores cognitivos de necesidad económica.

Entonces, el objetivo es analizar, mediante una entrevista a la víctima, un caso de violencia de género cometido en el Comité ejecutivo nacional del SUTERM y generar un diagnóstico que sirva para diseñar políticas de prevención. 


\section{Métodos}

A continuación, se explica la forma en que se hizo la investigación. Se describe el marco teórico, la entrevista como instrumento de investigación, así como su diseño y contenido.

\section{Marco teórico referencial}

El enfoque desde el cual se aborda la investigación es la criminología crítica, a partir de las aportaciones teóricas del doctor Augusto Sánchez Sandoval en su libro Epistemologías y sociología jurídica del poder. Ahí, el citado autor desarrolla las paradojas del Derecho (tabla 1) como un objeto espurio y esquizofrénico derivado del discurso de quienes ostentan poder político (Sánchez Sandoval 2012). Así, tales paradojas señalan:

Tabla 1. Paradojas del Derecho

\section{Paradoja}

1. "El derecho carece de identidad ontológica".

\section{Significado}

“La diferencia entre SER Y DEBER SER le sirve al derecho para inventar su origen. Es la paradoja que al distinguir oculta y produce información. El derecho no es un ser en el presente, sino un deber ser en el futuro, que podrá ser o no ser, que podrá cumplirse o no. Nadie tiene derechos sino hasta que después de un procedimiento judicial, que dura meses o años, se declara por un juez qué derecho asiste a qué persona [...]." (Sánchez Sandoval 2012)

“[...] al nombrarlo construye el riesgo de que alguien identifique su conducta con la definición jurídica, y pueda caer en las manos de sus operadores y represores.

2. "El poder que Igualmente, el poder fabrica a unos pocos delincuentes, seleccionándolos de entre manipula el derecho, crea el delito al definirlo". el total de ciudadanos, ya sean transgresores o inocentes, pues lo que se busca son "chivos expiatorios" que aun sin realizar conductas son privados de la libertad por ser considerados sospechosos de peligrosidad. Estas detenciones y sanciones le sirven a los aparatos del estado para calmar el temor colectivo, pero además lo reproduce porque le es funcional." (Sánchez Sandoval 2012)

3. "El derecho no se “El sistema jurídico está penetrado por otros sistemas ajenos como el político, controla a sí mismo". el económico, el religioso u otros sistemas de intereses [...]." (Sánchez Sandoval 2012)

"No puede evitar que en el mundo ocurra lo que ocurre. Hay normas cuyo fin se justifica por sus efectos preventivos, cuando el derecho solo actúa después de que los hechos han sucedido [...]." (Sánchez Sandoval 2012)

4. "El derecho penal

no puede prevenir"

De modo que el Derecho es entendido como un sistema de comunicación esquizofrénica que dice hacer cosas que no hace, como prevenir conductas o garantizar derechos y cuya aplicación depende de los intereses de personajes que tienen en sus manos poder político y económico. Así que los individuos que dependen del sistema 
se ven engañados con el discurso protector $y$, sin embargo, cuando se encuentran en la posición de víctima les es casi imposible acceder a una defensa adecuada de los derechos que se le hicieron creer (De Dios Mendoza 2017).

Igualmente, se han examinado las posturas feministas liberal y radical (Jaramillo 2009). La primera de ellas se centra en la búsqueda de la igualdad de derechos de la mujer frente al hombre, el derecho al voto y el acceso a la educación y a la vida laboral. ${ }^{1}$ La segunda pone su atención en el problema de la desigualdad entre hombres y mujeres desde la raíz del patriarcado; en su movimiento se incluyen marchas, protestas, toma de instalaciones gubernamentales y otras.

\section{Marco legal}

Con respecto a la normativa internacional, se revisaron diversos tratados internacionales firmados por México, como la Declaración Universal de los Derechos $\mathrm{Hu}$ manos; el Pacto Internacional de Derechos Económicos, Sociales y Culturales; así como la Convención sobre la Eliminación de Todas las Formas de Discriminación contra la Mujer (CEDAW) y la Convención Interamericana para prevenir, sancionar y erradicar la violencia contra la mujer (Convención De Belem Do Pará).

También, en el ámbito nacional, se estudiaron el delito de feminicidio en el Código Penal Federal, así como en diversas entidades federativas. Igualmente, la Ley General de Acceso de las Mujeres a una Vida Libre de Violencia, la Ley General para la Igualdad entre Mujeres y Hombres, la Alerta de Violencia de Género contra las Mujeres y la Ley Federal del Trabajo.

Concretamente, la investigación se limitó a las definiciones legales de violencia laboral por motivo de género y a la de violencia feminicida - esta última sólo como una referencia conceptual-, previstas previstas por la Ley General de Acceso de las Mujeres a una Vida Libre de Violencia:

\author{
Las postura \\ feminista liberal \\ se centra en la \\ búsqueda de \\ la igualdad de \\ derechos de la \\ mujer frente \\ al hombre, el \\ derecho al voto \\ y el acceso \\ a la educación \\ y a la vida laboral.
}


ARTÍCULO 10.- Violencia Laboral y Docente: Se ejerce por las personas que tienen un vínculo laboral, docente o análogo con la víctima, independientemente de la relación jerárquica, consistente en un acto o una omisión en abuso de poder que daña la autoestima, salud, integridad, libertad y seguridad de la víctima, e impide su desarrollo y atenta contra la igualdad.

Puede consistir en un solo evento dañino o en una serie de eventos cuya suma produce el daño. También incluye el acoso o el hostigamiento sexual.

ARTí́CULO 11.- Constituye violencia laboral: la negativa ilegal a contratar a la Víctima o a respetar su permanencia o condiciones generales de trabajo; la descalificación del trabajo realizado, las amenazas, la intimidación, las humillaciones, las conductas referidas en la Ley Federal del Trabajo, la explotación, el impedimento a las mujeres de llevar a cabo el período de lactancia previsto en la ley y todo tipo de discriminación por condición de género.

ARTículo 21.- Violencia Feminicida: Es la forma extrema de violencia de género contra las mujeres, producto de la violación de sus derechos humanos, en los ámbitos público y privado, conformada por el conjunto de conductas misóginas que pueden conllevar impunidad social y del Estado y puede culminar en homicidio y otras formas de muerte violenta de mujeres.

\section{Instrumento de investigación}

La investigación es de tipo cualitativa, basada en un estudio de caso para conocer la experiencia de una presunta víctima de violencia de género en el entorno laboral, cuyo dicho es analizado e interpretado con base en el marco teórico. Para ello, se diseñó una entrevista a una persona que señala ser víctima de violencia de género laboral. Este método fue elegido toda vez que, como parte del método cualitativo, se ha considerado una herramienta útil en la obtención de datos de forma directa a la versión de los sujetos inmiscuidos en los hechos (Fuster Guillen 2019).

Con el fin de dotar de alguna objetividad a la investigación, la entrevistada fue seleccionada porque ya ha presentado denuncias y se encuentra en trámite el juicio laboral ante la Junta Federal de Conciliación y Arbitraje con el número de expediente $1105 / 2019$. 
Cabe señalar que la entrevista fue grabada en video con autorización de la víctima y puede ser consultada en el portal de YouTube. ${ }^{2}$

Entonces, las preguntas se orientaron a los siguientes factores, extraídos de los artículos 10 y 11 de la Ley General de Acceso de las Mujeres a una Vida Libre de Violencia, interconectados por flechas como se aprecia en la figura 1:

Figura 1. Enfoque de la entrevista

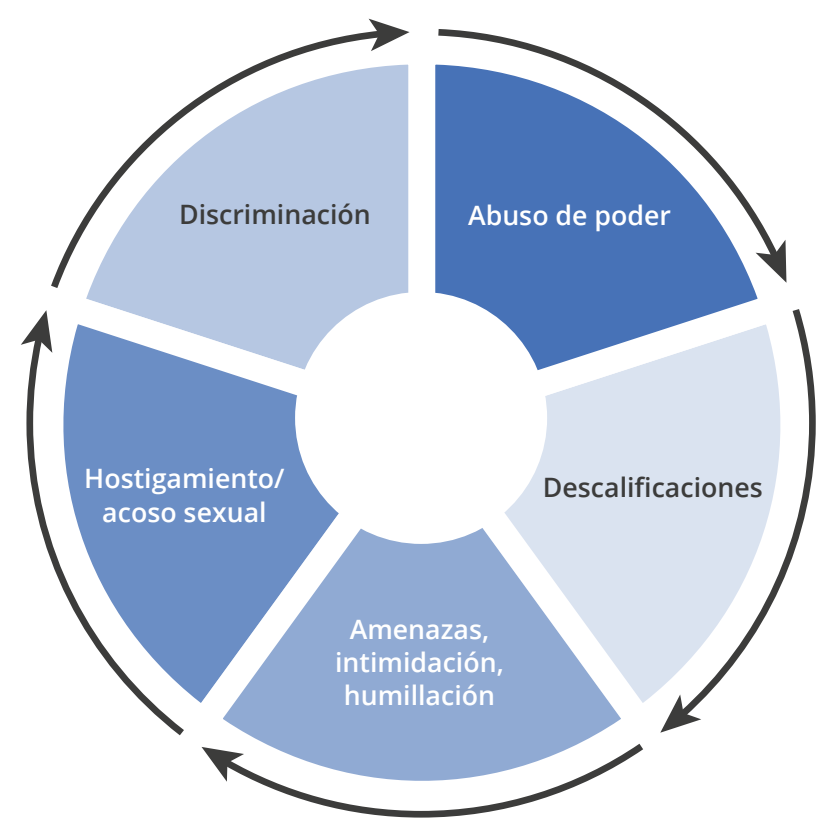

\section{Desarrollo}

\section{Antecedentes de violencia de género en México}

Al respecto, cabe apuntar que en México han existido casos relevantes de feminicidio, como los de Ciudad Juárez en 1993, durante el sexenio de Carlos Salinas de Gortari (Ronquillo 1999). En noviembre de 2009, durante el gobierno de Felipe Calderón, la Corte Interamericana de Derechos Humanos dictó el primer fallo internacional sobre feminicidio en contra del Estado mexicano por el caso del Campo Algodonero (Abramovich 2010; Aguirre 2014; Vázquez 2011).

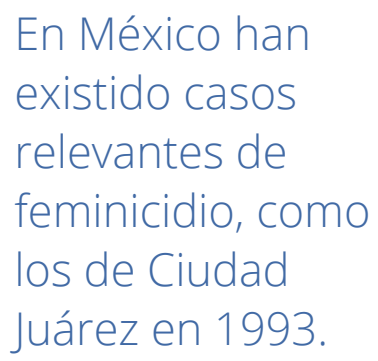

Otros casos recientes son los asesinatos de Fátima Cecilia Aldrighett Antón e Ingrid Escamilla, ambos durantela presidencia de Andrés Manuel López Obrador (BBC News 2020; Lima 2020); acontecimientos que motivaron a los legisladores a impulsar,

2 https://youtu.be/MWrvSSbqF6U Revisado el 7 de octubre, 2020. 
durante el año 2019, reformas al Código Penal Federal consistentes en sancionar hasta con 65 años de prisión el delito de feminicidio, cinco años más respecto a la pena anterior.

De acuerdo con datos de la Organización de las Naciones Unidas Mujeres México, el acumulado de defunciones femeninas con presunción de homicidio en los periodos de 1985 a 2017 fue de 55791 y de 2011 a 2017 de 18961 (ONU 2019). A su vez, el Secretariado Ejecutivo del Sistema Nacional de Seguridad Pública refiere que, entre enero y agosto de 2020 , se registraron 626 presuntos delitos de feminicidio a en el país (SESNSP 2020).

\section{Violencia de género en los centros laborales}

Muchos centros laborales también son fuente de violencia de género. De entrada, hay que considerar que la violencia laboral implica el sometimiento de la víctima a la voluntad de otro sujeto porque tiene miedo a más agresiones (Rogers y Kelloway 1997). Esta situación puede incluir violencia psicológica y física, las cuales pueden desembocar en la privación de la vida, violación, golpes, bullying, acoso sexual y otras (Chappell y Di Martino 2006).

Históricamente, los sindicatos han sido dominados por hombres dotados de poder político y económico. Ambos aspectos dan lugar a relaciones en donde las mujeres pueden quedar subordinadas a la voluntad del patrón y sufrir alguno de los tipos de violencia mencionados (Chappell y Di Martino 2006).

En México, la violencia laboral afecta a cifras no cuantificables de mujeres en sus centros laborales. A partir de la reforma del año 2019 a la Ley Federal del Trabajo, se incorporó la obligación del patrón de implementar, junto con sus trabajadores, protocolos para prevenir la discriminación por razones de género y para atender casos de violencia, acoso y hostigamiento sexual en los centros de trabajo (artículo 132, fracción XXXI).

En una investigación realizada por Ana Karen García (2019) se muestra que un mayor grado académico de las mujeres aumenta la probabilidad de ser víctima de discriminación, descalificaciones, maltratos, acoso o violencia sexual. Según sus resultados, de las mujeres analizadas que cuentan con licenciatura o posgrado, 33\% sufre este tipo de violencia; $18 \%$ son mujeres sin estudios, $20 \%$ con primaria, $27 \%$ con secundaria y $28 \%$ con preparatoria.

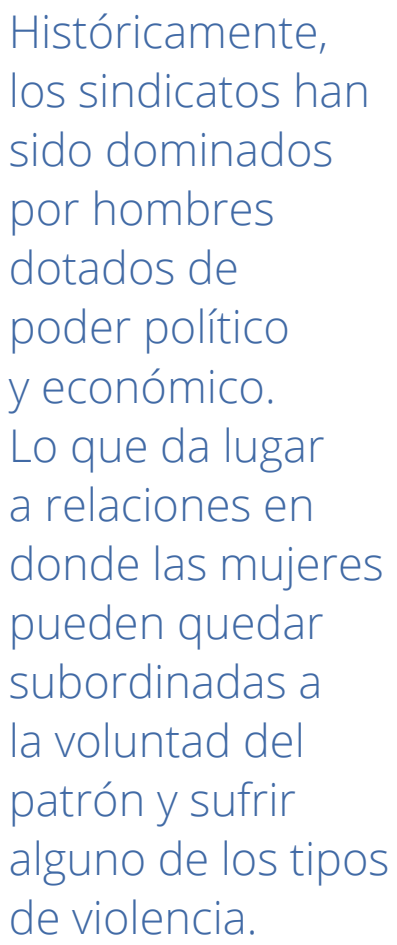

Históricamente, los sindicatos han sido dominados por hombres dotados de poder político y económico. Lo que da lugar a relaciones en donde las mujeres pueden quedar subordinadas a la voluntad del patrón y sufrir alguno de los tipos de violencia. 
La discriminación en contra de las mujeres se profundiza entre mayor es el nivel educativo que tienen $y$, por tanto, entre más alto es el puesto al que buscan acceder.

\section{Síntesis de la entrevista}

En el contexto señalado y con base en la ilustración 1, a continuación, en la tabla 2 se presenta una síntesis de la entrevista realizada. En la primera columna aparece el elemento de violencia de conformidad con los artículos 10 y 11 de la Ley General de Acceso de las Mujeres a una Vida Libre de Violencia; en segundo lugar, el minuto en que se hizo la pregunta y, en la última, una síntesis de la respuesta dada por la víctima:

Tabla 2. Síntesis de la entrevista

\section{Elemento}

Minuto

Respuesta (síntesis)

\begin{tabular}{|c|c|c|}
\hline Abuso del poder & $\begin{array}{l}\text { Toda la } \\
\text { entrevista }\end{array}$ & $\begin{array}{l}\text { La víctima refiere que ella es la proveedora en su familia, } \\
\text { lo cual incluye la atención de su madre, quien padece cáncer. }\end{array}$ \\
\hline $\begin{array}{l}\text { No respetar su } \\
\text { permanencia } \\
\text { o condiciones } \\
\text { generales de trabajo }\end{array}$ & $14: 00$ & $\begin{array}{l}\text { A la víctima se le negó el acceso a su oficina sin previo aviso, de un día } \\
\text { para otro, sin darle oportunidad de sacar sus pertenencias. }\end{array}$ \\
\hline Amenazas & $\begin{array}{l}11: 36 \\
15: 19 \\
42: 12\end{array}$ & $\begin{array}{l}\text { Recibió amenazas personales por no querer besar a su superior } \\
\text { y por desobedecer las sugerencias contrarias a sus labores; } \\
\text { también amenazas de muerte. }\end{array}$ \\
\hline Intimidación & $\begin{array}{l}24: 20 \\
42: 12\end{array}$ & $\begin{array}{l}\text { Iniciaron un proceso para rescindir su contrato con el fin de } \\
\text { intimidarla. Le hicieron llamadas amenazantes, incluso de muerte. }\end{array}$ \\
\hline Humillaciones & $\begin{array}{l}2: 34 \\
4: 27 \\
5: 00 \\
21: 20 \\
17: 34 \\
23: 10\end{array}$ & $\begin{array}{l}\text { La víctima refiere que las mujeres son vistas como objetos sexuales. } \\
\text { Abusaron de su necesidad económica, la hostigaron sexualmente, } \\
\text { recibió burlas por su despido y por la enfermedad de su madre. } \\
\text { Existe un dictamen pericial como prueba del daño } \\
\text { por violencia psicosocial que le causó su estadía en el SUTERM. } \\
\text { La desprestigiaron públicamente. }\end{array}$ \\
\hline $\begin{array}{l}\text { Discriminación } \\
\text { de género }\end{array}$ & $\begin{array}{l}2: 34 \\
37: 57 \\
38: 18\end{array}$ & $\begin{array}{l}\text { Las mujeres sólo son vistas como objetos sexuales, a las que } \\
\text { se quejan de acoso ante la comisión se les retiran sus derechos } \\
\text { sindicales. El representante jurídico minimiza las denuncias de acoso. }\end{array}$ \\
\hline Explotación & $\begin{array}{l}6: 19 \\
8: 37 \\
10: 20\end{array}$ & $\begin{array}{l}\text { Hay compañeras que son comisionadas para asistir a comidas } \\
\text { para deleite de integrantes del comité ejecutivo. A la víctima } \\
\text { se le saturó de actividades en diferentes áreas con el fin } \\
\text { de que presentara su renuncia. }\end{array}$ \\
\hline Violencia física & $15: 14$ & Su superior intentó besarla por la fuerza. \\
\hline $\begin{array}{l}\text { Hostigamiento/ } \\
\text { acoso sexual }\end{array}$ & $15: 14$ & Su superior intentó besarla por la fuerza. \\
\hline $\begin{array}{l}\text { Daños más allá } \\
\text { del contenido de la norma }\end{array}$ & 19:00 & $\begin{array}{l}\text { Depresión y posterior suicidio de un compañero colaborador } \\
\text { y ex esposo. }\end{array}$ \\
\hline
\end{tabular}




\section{Resultados}

En torno a la pregunta de investigación planteada: ¿cuáles son las características de la violencia de género contra una mujer en el entorno laboral de un sindicato? De acuerdo con la entrevista, la presunta víctima ha sufrido diversos daños, los cuales han sido clasificados de acuerdo con los señalados en el artículo 10 de la Ley General de Acceso de las Mujeres a una Vida Libre de Violencia: daños a la autoestima, salud, integridad, libertad y seguridad de la víctima, limitación a su desarrollo y transgresión a la igualdad. Estas características han sido relacionadas con las categorías utilizadas en la tabla 3:

Tabla 3. Efectos de la violencia de género en el entorno laboral de un sindicato

\begin{tabular}{|c|c|c|c|c|}
\hline $\begin{array}{l}\text { Abuso } \\
\text { del poder }\end{array}$ & Descalificaciones & $\begin{array}{l}\text { Amenazas, } \\
\text { intimidación } \\
\text { y humillación }\end{array}$ & $\begin{array}{l}\text { Hostigamiento } \\
\text { o acoso sexual }\end{array}$ & Discriminación \\
\hline $\begin{array}{l}\text { Sometimiento } \\
\text { por cuestiones } \\
\text { económicas }\end{array}$ & $\begin{array}{l}\text { Daño a la } \\
\text { autoestima }\end{array}$ & $\begin{array}{l}\text { Daño a la } \\
\text { autoestima }\end{array}$ & $\begin{array}{l}\text { Daño a la } \\
\text { autoestima }\end{array}$ & $\begin{array}{l}\text { Daño a la } \\
\text { autoestima }\end{array}$ \\
\hline $\begin{array}{l}\text { Hostigamiento } \\
\text { o acoso sexual }\end{array}$ & Seguridad & Seguridad & Seguridad & Seguridad \\
\hline Discriminación & Salud & Salud & Salud & Salud \\
\hline $\begin{array}{l}\text { Amenazas, } \\
\text { intimidación } \\
\text { y humillación }\end{array}$ & Integridad & Integridad & Integridad & Integridad \\
\hline Descalificaciones & & & Libertad & \\
\hline
\end{tabular}

Como es posible apreciar, la violencia laboral puede tener efectos diversos en cada categoría; asimismo, puede existir el mismo tipo de efecto en más de una. Por ejemplo, la salud mental se puede ver afectada por la descalificación y por una amenaza. Igualmente, una categoría puede causar diversos efectos, tal es el caso del acoso que puede afectar la autoestima, la salud, la libertad, la integridad.

A lo anterior, en el caso de estudio se suman los efectos que van más allá de la víctima y que impactan en familiares, mismos que para efectos de este artículo llamamos "onda expansiva". En este caso, el daño que destaca es el suicidio del ex-esposo de la afectada, el cual, según ella misma cuenta en la entrevista, también colaboraba con el SUTERM, gracias a su relación con la entrevistada. De ahí que, a juicio de ella, uno de los pretextos creados para despedirla de su puesto de trabajo fue crear la acusación, injustificada, de que él había realizado manejos indebidos, que la beneficiaban a ella, de los asuntos y recursos que se le habían asignado. Por tales actos, 
los dos fueron expuestos de forma pública, razón por la que él padeció depresión y se suicidó. Cabe reiterar que ésta es la perspectiva de la entrevistada.

Igualmente, puede existir violencia de parte de instituciones gubernamentales; en este caso, y a decir de la víctima, como la Junta Federal de Conciliación y Arbitraje al dejar de aplicar la perspectiva de género y hacer comentarios intimidatorios. De tal manera, la tabla 3 debe ser completada con la información incluida en la tabla 4:

Tabla 4. Daños adicionales derivados de la violencia de género
Violencia que proviene de instituciones gubernamentales

Suicidio de personas cercanas a la víctima.

Inaplicación de la perspectiva de género y emisión de comentarios intimidatorios.

En consecuencia, es posible decir que se ha comprobado, para el caso en análisis, la hipótesis de que las mujeres se someten al poder y violencia laboral del patrón, condicionadas por factores cognitivos de necesidad económica. Como resultado adicional, esa violencia provoca daños graves más allá de la figura de la víctima, es decir, en su familia y personas cercanas.

\section{Discusión}

\section{Sometimiento condicionado por factores económicos}

En el caso analizado (y en muchos casos puede replicarse), las mujeres aceptan la violencia a la que son sometidas. Esta situación está condicionada, es decir, por alguna circunstancia la mujer no es libre de tomar una decisión o una acción.

El factor económico es el más importante para esta aceptación de la violencia y los daños causados. Por ejemplo, conservar el trabajo u obtener una mejora laboral son factores que implican dinero y que están en manos de un sujeto que tiene el poder para tomar una decisión favorable o no. Esto puede condicionar algunas conductas de la mujer y del patrón en el sindicato.

Estas conductas no son libres, están determinadas por la relación de poder que pone en manos del patrón el bienestar económico de la mujer, de su familia y personas allegadas.

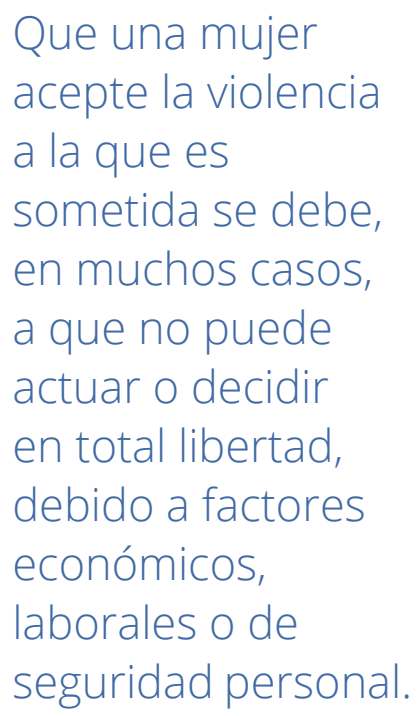

Que una mujer acepte la violencia a la que es sometida se debe, en muchos casos, a que no puede actuar o decidir en total libertad, económicos, laborales o de seguridad personal. 


\section{La ley en contra de la violencia de género carece de identidad ontológica}

Si bien es cierto que en México existe legislación que intenta eliminar un mal como la violencia de género, parece que existen casos con resultados a la inversa. Lamentablemente, el sistema político -en este caso la autoridad sindical que ejerce violencia- no entiende que el derecho tiene la cualidad de ser contingente, es decir, puede o no surtir los efectos para los que fue creado.

Además, pareciera que aquellos que están obligados a cumplirla, como las autoridades sindicales del caso analizado, no tienen el interés real de ajustarse a esas disposiciones. Por el contrario, el caso analizado refleja que el poderoso ejerce violencia sobre las mujeres sin importar el contenido de la legislación o de las acciones que, supuestamente, se aplican en la organización sindical.

Es preciso hacer hincapié en este punto, pues la evidencia muestra que pesa más en la balanza de la justicia lo político y lo económico que representan los líderes sindicales, que la ley en la voluntad de las autoridades encargadas de proteger a las víctimas.

Así, en el caso analizado, y en aquellos similares, los trabajos legislativos y ejecutivos que se llevan a cabo se convierten en un discurso político que sirve de paliativo para las agredidas y con ello mandan mensajes que avalan la lucha contra la violencia referida, aunque ni siquiera existe la intención de erradicarla.

En consecuencia, en el entorno laboral del caso estudiado, la legislación para combatir la violencia de género pertenece al mundo del "deber ser", que no sirve para prevenir actos de violencia contra las mujeres, pero que con su existencia intenta ocultar los abusos de poder que existen en los espacios de trabajo.

\section{Las autoridades sindicales manipulan la ley y radicalizan la violencia}

Al tratarse del "deber ser", el derecho es aprobado por personajes con poder político y económico cuyos intereses particulares determinan su contenido y aplicación. Como se puede ver en la tabla 3, las autoridades del sindicato abusaron de su poder y de su dinero sin recibir una sanción por parte de la propia institución o la empresa para la que trabajan.

Difícilmente el derecho que es aplicable para todos es aplicado para investigar a los dirigentes sindicales, por lo menos. Infortunadamente, en el caso estudiado,




y podrían existir otros, los reglamentos o normas creados en el sindicato no son aplicados en contra de los dirigentes, ya que han sido elaborados por ellos o por su mandato y este descontrol puede derivar en la denominada violencia laboral.

En el mismo sentido, es paradójico que quien ejerce violencia laboral es también quien crea las acciones o políticas para erradicarla. Esta situación hace que la violencia de género sea más dura o se radicalice y cause el efecto expansivo señalado en la tabla 4 .

Entonces, lo que se vive en el centro laboral sindical es una violencia de género que sólo pueden ver quienes allí trabajan y como quien ejerce la violencia ostenta poder, no existen límites ni sanciones que eviten la violencia laboral, incluidos los daños a la familia o a personas cercanas a las víctimas.

\section{La ley contra la violencia de género es controlada por intereses políticos}

Vinculado con lo anterior, la legislación en materia de género, que incluye la interna de los sindicatos, tiene su origen en los intereses políticos de los dirigentes sindicales. Esto implica que aceptan la existencia de las normas, pero ellos deciden el contenido y si la acatan o no.

Por eso, en casos como el estudiado, aunque existe un derecho que intenta prevenir y sancionar la violencia de género, esa existencia radica en la construcción de un discurso a favor de los derechos de la mujer, cuyo objetivo real es el posicionamiento político del propio agresor.

\section{La ley contra la violencia de género no puede prevenir}

El derecho, al estar referido al futuro, no puede prevenir conductas sancionables como la violencia de género. Esta característica del derecho se fortalece al quedar sometido al poder y voluntad de las autoridades sindicales que ejercen violencia laboral.

Los sindicatos son lugares propicios para los casos de violencia de género. De entrada, la naturaleza de las relaciones laborales implica subordinación, misma que se refuerza con el control económico que ahí existe. Además, pareciera que son lugares oscuros, en los que no es tan fácil visibilizar los casos que se suscitan.

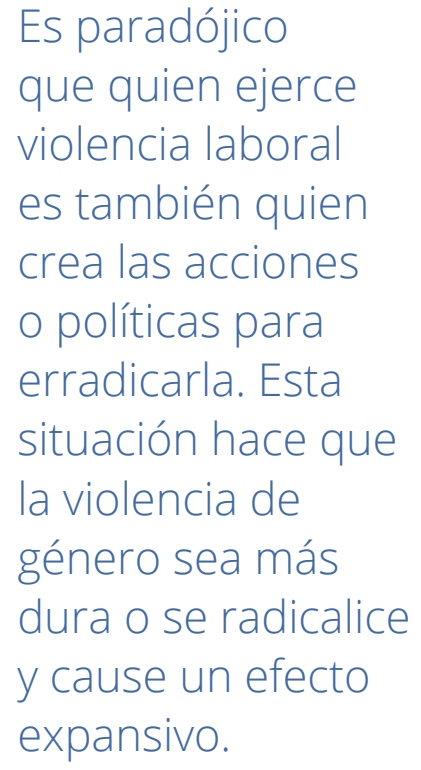


Por lo tanto, un sindicato puede convertirse en un punto donde las condiciones de poder debilitan al sistema jurídico, el cual, menos aún, está en posibilidades de prevenir y sancionar la violencia de género.

\section{La violencia de género en el sindicato incluye la que proviene de instituciones gubernamentales}

Los sindicatos, sobre todo el SUTERM, son centros de mucho poder económico y político, con mucha influencia en otras instancias, como el Poder Ejecutivo y Legislativo. Lo mismo sucede con la Junta de Conciliación y Arbitraje, la cual puede quedar sometida a las amenazas de los sindicatos y resolver casos a favor de estos últimos (tabla 4).

En síntesis, la violencia laboral de un sindicato poderoso puede ejercerse desde las instituciones como las Juntas de Conciliación y Arbitraje.

\section{Conclusiones}

Las conclusiones que a continuación se señalan sólo pueden aplicarse al caso de estudio de la presente investigación, no pueden ser generalizadas, toda vez que se trata de una sola persona entrevistada.

Primera. La aceptación de la violencia de género que hace una mujer en el entorno laboral del SUTERM, no es libre, está condicionada por la relación de poder que pone en manos del patrón el bienestar económico de la mujer, de su familia y de personas allegadas.

Segunda. En el entorno laboral del SUTERM, la legislación para combatir la violencia de género pertenece al mundo del "deber ser", que no sirve para prevenir actos de violencia contra las mujeres, pero que con su existencia intenta ocultar los abusos de poder que existen en esos espacios de trabajo.

Tercera. Lo que se vive en el centro laboral del SUTERM es una violencia de género que sólo pueden ver quienes allí trabajan $\mathrm{y}$, como quien ejerce violencia ostenta poder, no existen límites ni sanciones que eviten la violencia laboral, incluidos los daños a la familia o personas cercanas a las víctimas.

Cuarta. En casos como el estudiado, aunque existe un derecho que intenta prevenir y sancionar la violencia de género, esa existencia radica en la construcción de un 


\section{discurso a favor de los derechos de la mujer cuyo objetivo real es el posicionamiento político del propio agresor.}

\section{Quinta. En el entorno laboral del SUTERM la violencia se traduce en la existencia de condiciones de poder que debilitan al sistema jurídico, el cual, menos aún, está en posibilidades de prevenir y sancionar la violencia de género.}

\section{Sexta. La violencia laboral practicada por el SUTERM puede ejercerse desde las ins- tituciones, como las Juntas de Conciliación y Arbitraje._}

\section{Referencias}

Abramovich, Víctor. 2010. "Responsabilidad estatal por violencia de género: comentarios sobre el caso 'Campo Algodonero' en la Corte Interamericana de Derechos Humanos." Anuario de Derechos Humanos, no. 6, 167-182. https://doi.org/10.5354/0718-2279.2010.11491

Aguirre, Olivia. 2014. "Estado mexicano: lejos de cumplir íntegramente la sentencia de la CIDH en el caso González y otras ('Campo Algodonero')." Revista VIA IURIS, no. 17, 169-182. https://www.redalyc.org/articulo. oa?id=273940436009 Revisado el 7 de octubre, 2020.

BBC NEWS. 2020. "Caso Fátima: lo que se sabe del asesinato y tortura de la niña de 7 años cuyo caso conmociona a México." ввс News Mundo, 7 de octubre, 2020. https://www.bbc.com/mundo/noticias-americalatina-51540101 Revisado el 7 de octubre, 2020.

Chappell, Duncan, and Di Martino, Vittorio. 2006. Violence at Work. Ginebra: International Labour Organization.

De Dios Mendoza, Verónica. 2017. “¿Qué es realmente el feminismo radical?" Hechos y Derechos, no. 40 (julio-agosto). https://revistas.juridicas.unam.mx/ index.php/hechos-y-derechos/article/view/11546/13423 Revisado el 7 de octubre, 2020.

Fuster Guillen, Doris Elida. 2019. "Investigación cualitativa: Método fenomenológico hermenéutico". Propósitos y Representaciones 7, no. 1 (enero-abril): 201-229. http://dx.doi.org/10.20511/pyr2019.v7n1.267

García, Ana Karen. 2019. "Más estudios pueden significar más violencia laboral para las mujeres." El Economista, 6 de octubre, 2019. https://www.eleconomista.com.mx/ arteseideas/Mas-estudios-pueden-significar-masviolencia-laboral-para-las-mujeres-20191006-0005. html Revisado el 7 de octubre, 2020.

Jaramillo, Isabel. 2009. "La crítica feminista al derecho". En El género en el derecho. Ensayos críticos, compilado por Ramiro Ávila Santamaría, Judith Salgado y Lola Valladares, 103-136. Ecuador: Ministerio de Justicia y Derechos Humanos.
Ley Federal del Trabajo. 2015. México: Congreso de la Unión. https://www.gob.mx/cms/uploads/attachment/ file/156203/1044_Ley_Federal_del_Trabajo.pdf Lima, Lioman. 2020. "Feminicidio de Ingrid Escamilla: por qué el asesinato de la joven ha provocado protestas en México." BBC News Mundo, 16 de febrero, 2020. https://www.bbc.com/mundo/noticias-americalatina-51518716 Revisado el 7 de octubre, 2020.

onU Mujeres México. 2019. Violencia Feminicida en México. https://mexico.unwomen.org/es/digiteca/ publicaciones/2019/05/infografia-violenciafeminicida-en-mexico

Rogers, K. A. and E. K. Kelloway. 1997. "Violence at work: Personal and organizational outcomes." Journal of Occupational Health Psychology 2, no. 1: 63-71. https://doi.org/10.1037/1076-8998.2.1.63

Ronquillo, Víctor. 1999. Las muertas de Juárez: crónica de una larga pesadilla. México: Editorial Planeta.

Sánchez Sandoval, Augusto. 2012. Epistemologías y sociología jurídica del poder. México: UNAM-Facultad de Estudios Superiores Acatlán-DGAPA.

Secretariado Ejecutivo del Sistema Nacional de Seguridad Pública. 2020. Información sobre violencia contra las mujeres (Incidencia delictiva y llamadas de emergencia 9-1-1), agosto 2020. México: Secretariado Ejecutivo del Sistema Nacional de Seguridad Pública. https:// drive.google.com/file/d/1IAN68eTY8ZoXuoJoW4uTpyZwbiS913H/view Revisado el 7 de octubre, 2020.

Vázquez, Santiago. 2011. 'El caso 'campo algodonero' ante la Corte Interamericana de Derechos Humanos." Anuario de derecho internacional, no. 11 (enero): 515-559. http://www.scielo.org.mx/scielo.php? $\underline{\text { script }=\text { sci_arttext } \& \text { pid }=S 1870-46542011000100018}$ Revisado el 7 de octubre, 2020. 